Revista Española de Antropología Americana ISSN: 0556-6533

http://dx.doi.org/10.5209/reaa.71751

Etnografía de los medios de comunicación indígenas y afroamericanos: propuestas metodológicas

\author{
Coordinado por Gemma Orobitg ${ }^{1}$
}

\title{
Introducción al dossier
}

\section{Gemma Orobitg}

Este dossier presenta una reflexión sobre el método etnográfico basada en experiencias de campo en culturas indígenas y afroamericanas de América Latina. El objetivo del conjunto de estas investigaciones es el estudio comparativo de las prácticas de la comunicación por parte de los colectivos indígenas y afroamericanos, sus usos efectivos de las tecnologías de comunicación, así como el impacto social de estos medios $^{2}$.

El análisis de la comunicación tecnológicamente mediada a través de las producciones propias de radio, video y en las redes sociales, constituye un campo secundario de la etnografía sobre las culturas indígenas y afroamericanas. Esto explica que aún no se haya producido ningún debate sobre los retos metodológicos que suponen estas investigaciones. En otras palabras, no se ha avanzado aún en la reflexión sobre qué tipo de innovaciones metodológicas implica el estudio de un ámbito tan actual de la experiencia indígena y afroamericana como es el de los medios de comunicación propios.

El enfoque general de los artículos del dossier es que los usos indígenas y afroamericanos de las tecnologías de comunicación revelan la relación de estas poblaciones con la modernidad. Las colectividades amerindias y afroamericanas modernizan los medios cuando los usan según unos "estilos" propios vinculados a sus teorías de la comunicación y a sus intereses en un mundo global del que, salvo algunas excepciones, no desean quedar al margen. Desde esta perspectiva, los autores que participan en este dossier, con amplia experiencia de investigación de campo en culturas indígenas y afroamericanas, plantean propuestas que actualizan los debates relativos a la

\footnotetext{
Departamento de Antropología Social, Universidad de Barcelona. orobitg@ub.edu.

2 Los artículos que se reúnen en el dossier forman parte de los resultados de un programa de estudios de larga duración que, con el título de "Medios indígenas", reúne a investigadores de varias universidades españolas, así como de universidades latinoamericanas y europeas. Este programa de estudios se ha organizado principalmente alrededor de dos proyectos de investigación I+D correlativos, financiados por el Ministerio de Ciencia, Innovación e Universidades del Gobierno de España: "Pueblos indígenas, medios de comunicación y significados del conflicto en América Latina (2016-2018)" y "Comunicación indígena y patrimonio cultural en América Latina: conservación, revitalización, creatividad” (2019-2021).
} 
metodología etnográfica. El orden de los artículos permite transitar desde los debates metodológicos más generales hasta cuestiones de método más específicas basadas en las reflexiones sobre el desarrollo del trabajo de campo.

El dossier se inicia con la discusión sobre las nociones de participación, colaboración, así como de etnografía plural o multivocal. Dentro de este debate, la multimodalidad o el uso de distintos formatos -principalmente, textual, hipertextual, visual y audiovisual- tanto para apoyar el desarrollo de las investigaciones como para la presentación de los resultados, es una cuestión ampliamente desarrollada. Estos son, en síntesis, los aspectos claves de la propuesta metodológica común a todas las aportaciones.

Adicionalmente, los dos artículos que abren el dossier -el primero que analiza la web MEDIOS INDIGENAS y el segundo sobre la realización de la serie documental, La comunicación indígena: un derecho en construcción-discuten sobre las implicaciones metodológicas e interpretativas de hacer del objeto de investigación -en este caso los medios de comunicación- una herramienta de investigación, al mismo tiempo, que una forma de "escritura" etnográfica y una ampliación del campo de investigación. Esta imbricación entre las dimensiones que estructuran la pesquisa etnográfica -objeto, método, escritura e impacto social de la investigación-se materializa en los medios de comunicación creados para el desarrollo del proyecto, particularmente, la web y la serie documental. La creación de estos medios propios del proyecto responde a su objetivo general de asegurar una investigación colaborativa, participativa y plural. Efectivamente, estas plataformas de comunicación creadas desde el proyecto funcionan como medios que permiten investigar a partir del reconocimiento y del diálogo con los comunicadores y usuarios de los medios indígenas y afroamericanos. Igualmente, estos medios permiten actualizar la exposición de los objetivos de la comunicación, así como los debates que generan continuamente los colectivos indígenas y afroamericanos en el mismo ejercicio de su comunicación. A este respecto, en relación con la elaboración de la etnografía, quedan en disputa la noción de autoría única -en el sentido de la autoridad interpretativa de un solo narrador-, así como la idea de resultado de investigación -pensado como una síntesis final interpretativa-. En su lugar, se debate sobre la noción de coautoría y sobre la idea de la etnográfica como de una obra abierta y dinámica -como las realidades indígenas y afroamericanas implicadas en el proyecto- en la que cada etapa de la investigación aporta unos resultados con relevante valor analítico, aunque puedan ser ampliados o, incluso, cuestionados por el avance de la investigación. En fin, una propuesta metodológica con esta característica precisa también de una reflexión sobre el formato, los lenguajes y los géneros de la obra etnográfica.

A continuación, los siguientes artículos del dossier, a partir de experiencias concretas de trabajo de campo, sustentan la propuesta de la imbricación necesaria entre la etnografía sobre el terreno y la etnografía online. El tercer artículo de la selección, centrado en un trabajo de campo sobre el activismo digital indígena en Panamá y Guatemala y el cuarto, sobre la radiodifusión indígena y comunitaria en el noroeste argentino, refuerzan la idea de que Internet, lejos de ser experimentado como un ciberespacio, se presenta en relación de continuidad con la vida social offline. En este sentido se plantea que la investigación etnográfica debe tanto mapear y entender los entornos online, como observar la influencia de estos en la conformación y modificación de los sistemas sociales. La idea central es que, en la etnografía indígena actual, la separación del espacio online y offline ofrece únicamente una representación par- 
cial de la experiencia del mundo tal como se presenta a los etnógrafos en el trabajo de campo. En el artículo sobre el activismo digital en defensa de la propiedad intelectual de los tejidos indígenas, se expone cómo diferentes legislaciones, en Panamá y en Guatemala, explican los usos políticos diferenciados de las redes sociales que puede observarse en ambos casos. En el texto sobre la radiodifusión indígena en el noroeste argentino se explica cómo el panorama de las radios indígenas y comunitarias, que puede reconstruirse a partir de una investigación online, queda incompleto sin una etnografía de la radio sobre el terreno que aborde aspectos tan diversos como la historia de las radios, las experiencias de sus comunicadores y de sus oyentes o sus vínculos con los procesos sociopolíticos. Ambos artículos justifican porqué el diseño de la etnografía indígena debe tener en cuenta ambos escenarios, online y offline. En este sentido, el objeto de investigación se representa como necesariamente deslocalizado o, en cierta medida, relocalizado, poniéndose a debate la noción tradicional de comunidad. Igualmente, queda cuestionada la dicotomía, realidad/virtualidad.

El quinto artículo del dossier trata sobre la etnografía de los festivales de cine indígena en comunidades indígenas en Colombia y Panamá. Su idea principal es que los videos producidos por los realizadores indígenas representan sólo el punto de partida para pensar una antropología del audiovisual indígena. Dicho de otro modo, la etnografía del cine indígena no puede restringirse al análisis de los procesos de producción y del contenido de los audiovisuales, sino que debe tener en cuenta las experiencias de recepción -por parte de públicos indígenas y no indígenas- de estas producciones. El principal objetivo es analizar qué tipo de relaciones y procesos sociales activa el video indígena -por ejemplo, de identificación comunitaria, de internacionalización de las demandas indígenas o de consensos para el futuro de las sociedades indígenas-. Esta propuesta implica igualmente, como puede verse también en los artículos sobre el activismo digital y la radiodifusión indígena, un cuestionamiento de los principios sobre los cuales se define el objeto/campo de la investigación etnográfica. En el caso de la etnografía del cine indígena, su estudio, basado en las distintas experiencias de su recepción, subvierte los dualismos clásicos, centro/periferia y mundo indígena/mundo no indígena.

El sexto artículo del dossier presenta una reflexión sobre el trabajo de campo online en una investigación sobre la Santería en Barcelona -realizado paralelamente, y de forma imprevista, al trabajo sobre el terreno-. En este caso, "santeros tradicionales" y "neosanteros" utilizan Internet tanto para su organización interna y ritual como para visibilizarse, con el objetivo, por un lado, de rebatir la estigmatización social de la Santería y, por otro, mostrar su especificidad dentro de la característica heterogeneidad de esta religión afroamericana. Este es el resultado de un proceso, de progresiva digitalización de la práctica del culto y de la transmisión de los conocimientos que permiten la iniciación a la Santería, que es directamente observado y experimentado por la etnógrafa. Hasta el punto, que, para su sorpresa, se ve implicada, a petición de los santeros, en este proceso - por ejemplo, realizando grabaciones o tomando fotografías, hasta el momento prohibidas, que circularán después en las redes, o participando en el diseño de una página web sobre el culto que no acabó de concretarse-. Esta particular experiencia de trabajo de campo permite reformular la noción clásica de observación participante imbricando la participación de la antropóloga sobre el terreno y online. Se trata de una actualización de la definición de observación participante que tiene relevantes consecuencias metodológicas. Por un lado, implicaciones en la definición del objeto/campo. En concreto, supone la inclusión, 
en el estudio de la Santería, de la emergencia de la e-Santería. Por otro lado, repercusiones a nivel del análisis, en particular, la reformulación de un concepto como el del secreto, tan específicamente asociado, hasta el momento, a la caracterización de la Santería. El secreto, observa la etnógrafa, es objeto de una discusión en las redes que contribuye a definir y delimitar lo que es hoy la Santería. En fin, se trata de un nuevo ejemplo que apoya la idea de una etnografía en la que deben superponerse las dimensiones online y offline, pero en este caso constatando la inherente ampliación del ejercicio de la observación participante a ambas dimensiones.

El séptimo y último artículo del dossier explica que el cuerpo funciona como un medio de comunicación propio para las poblaciones quilombolas de la Amazonia brasileña. La idea central es que a través de una etnografía del cuerpo es posible repensar recursivamente algunas interpretaciones bien establecidas sobre la comunicación y su dimensión política. Desde esta perspectiva, se propone una reflexión crítica sobre los límites conceptuales y políticos de la etnografía. Por un lado, se plantea la necesidad de repensar recursivamente nuestros conceptos teniendo en cuenta las formas locales de identificación - o auto-representación- y de comunicación política. Un ejemplo de ello puede encontrarse en los experimentos comunicativos en los que se han involucrado chamanes indígenas y climatólogos en los que cada uno intenta utilizar los medios de comunicación del otro, respectivamente, el lenguaje del cuerpo y el lenguaje escrito. Por otro lado, este último artículo previene sobre los riesgos de una investigación etnográfica que se define como políticamente comprometida pero que se fundamente en la idea occidental de la representación política. En este caso, la principal contingencia que afronta la etnografía, sobre la base de la supuesta ubicuidad y transparencia de los medios de comunicación, es la de reificar las diferencias sociales y políticas al interior de los colectivos quilombolas -pero también puede aplicarse al caso indígena- que se vehiculan, en este caso, a través de la práctica de la comunicación tecnológicamente mediada. Desde la perspectiva local, es relevante la constatación de que la consolidación de una élite política de comunicadores no entra dentro de los intereses colectivos de la comunicación. En este sentido, lo que se propone es que el tipo de compromiso político de la etnografía es algo a construir durante el mismo desarrollo de la investigación tomando en consideración las ideas y conceptos locales sobre la representación y la comunicación.

En conclusión, los artículos reunidos en este dossier demuestran como la experimentación define la etnografía, en tanto práctica sobre el terreno y como trabajo de escritura. La metodología etnográfica debe articularse con las particularidades sociopolíticas y ontológicas, a menudo heterogéneas, de los colectivos implicados en la investigación. En este sentido aspectos claves del método etnográfico como la delimitación del objeto/campo, las nociones de autoría y resultado, las características de la "escritura etnográfica", las repercusiones sociales de la investigación, así como la idea de una investigación políticamente comprometida, deben ser constantemente actualizadas. El interés de las antropólogas y antropólogos que participan en el dossier es que sus experiencias de trabajo de campo aporten ejemplos e ideas substanciales a estos debates metodológicos. 